\title{
PENGEMBANGAN STRATEGI PEMBELAJARAN DALAM PENDIDIKAN MATEMATIKA
}

\author{
Oleh: Nur Rahmah \\ Dosen Prodi Pendidikan Matematika STAIN Palopo \\ E-mail: prodimat stainplp@yahoo.co.id
}

\begin{abstract}
Abstrak:
Strategi pembelajaran menggambarkan komponen umum materi pembelajaran dan prosedur yang digunakan dalam mencapai hasil belajar. Konsep strategi pembelajaran tergambar dalam peristiwa pembelajaran sebagaimana yang dijelaskan secara perinci dalam bukunya Gagne yang berjudul The Condition of Learning and Theory of Instruction (1985). Peristiwa pembelajaran adalah gambaran sederhana tentang paradigma aktivitas peserta didik dan pendidik yang terjadi secara komplementer (saling isi-mengisi) dan saling ketergantungan dalam situasi belajar. Peristiwa belajar menggambarkan aktivitas peserta didik dalam menerima, mempraktikkan, menciptakan, dan lain-lain. Peristiwa pembelajaran menggambarkan aktivitas pendidik dalam memindahkan ilmu, membina, memberikan kenyamanan belajar, dan lain-lain
\end{abstract}

Kata Kunci: Pengembangan, Strategi Pembelajaran, Matematika

\section{Pengantar}

Beberapa istilah yang hampir sama dengan strategi pembelajaran yaitu pendekatan, metode, teknik, atau taktik dalam pembelajaran. Pendekatan (approach) menetapkan arah umum atau lintasan yang jelas untuk pembelajaran yang mencakup komponen yang lebih tepat atau perinci. Misalnya istilah problem-based learning (pembelajaran berbasis masalah), experiental learning (pembelajaran berbasis pengalaman), direct instruction (pembelajaran langsung), dan simulation (simulasi). Semua istilah tersebut merujuk pada pendekatan pembelajaran dimana metode (komponen) merupakan cakupannya (Reigeluth and Chellman, 2009). "An approach is a set of correlative assumption dealing with the nature of language teaching and learning. An approach is axiomatic wich describes nature of the subject matter to be taught (Richards and Rodgers, 1986:9)".

Dapat juga dikatakan bahwa pendekatan merupakan sudut pandang bagi guru, dosen, atau instruktur atau pengembang terhadap proses pembelajaran seperti pendekatan yang berpusat pada guru, dosen, instruktur (teacher-centred approaches) dan pendekatan yang 
berpusat pada peserta didik (student-centred approaches). Pendekatan kepada guru menurunkan strategi pembelajaran langsung (direct instruction), pembelajaran deduktif, atau pembelajaran ekspositori. Adapun pendekatan pembelajaran yang berpusat pada peserta didik menurunkan strategi pembelajaran discovery dan inkuiri serta strategi pembelajarn induktif (Direktorat Tenaga Kependidikan, 2008: $5)$.

Metode merupakan upaya untuk mengimplementasikan rencana yang sudah disusun dalam kegiatan nyata agar tujuan tersebut tercapai secara optimal. Metode digunakan untuk merealisasikan strategi yang telah ditetapkan. Strategi merujuk pada suatu perencanaan untuk mencapai sesuatu, sedangkan metode adalah cara yang dapat digunakan untuk melaksanakan strategi (Direktorat Tenaga Kependidikan, 2008: 3). Tidak semua metode cocok digunakan untuk mencapai tujuan pembelajaran tertentu. Hal ini tergantung dari karakteristik peserta didik, materi pembelajaran, dan konteks lingkungan dimana pembelajaran berlangsung. Metode-metode yang diterapkan dalam pembelajaran misalnya metode ceramah, demonstrasi adalah diskusi, simulasi, pemberian tugas dan resitasi, tanya jawab, pemecahan masalah, sistem regu, metode latihan (drill), karyawisata (field trip), ekspositori, inkuiri, kontekstual, bermain peran, induktif, dan deduktif. Metode tersebut hanyalah sebagian kecil dari paling tidak sekitar dua puluh metode (Suparman, 2012).

Teknik bersifat implementatif yang terjadi dalam ruang kelas. Teknik harus sesuai dengan metode dan pendekatan. Adapun taktik dalam pembelajaran merupakan gaya yang diperankan oleh pendidik secara individu dalam mengimplementasikan teknik atau metode tertentu. Oleh karena itu, dalam tulisan ini akan dibahas mengenai bagaimana melakukan pengembangan strategi pembelajaran dalam pendidikan matematika.

\section{Pembahasan}

Strategi pembelajaran menggambarkan komponen umum materi pembelajaran dan prosedur yang digunakan dalam mencapai hasil belajar. Konsep strategi pembelajaran tergambar dalam peristiwa pembelajaran sebagaimana yang dijelaskan secara perinci dalam bukunya Gagne yang 
berjudul The Condition of Learning and Theory of Instruction (1985). Peristiwa pembelajaran adalah gambaran sederhana tentang paradigma aktivitas peserta didik dan pendidik yang terjadi secara komplementer (saling isi-mengisi) dan saling ketergantungan dalam situasi belajar. Peristiwa belajar menggambarkan aktivitas peserta didik dalam menerima, mempraktikkan, menciptakan, dan lain-lain. Peristiwa pembelajaran menggambarkan aktivitas pendidik dalam memindahkan ilmu, membina, memberikan kenyamanan belajar, dan lain-lain (Leclercg dan Poumay, 2011).

Gagne (2005) menjabarkan peristiwa belajar atau dikenal dengan the nine event of instruction yang dihubungkan dengan strategi pembelajaran, yang mencakup:

1) Gaining attention (menarik perhatian);

2) Informing learners of the objective (menjelaskan tujuan pembelajaran);

3) Stimulating recall of prior learning (mengingatkan pengetahuan sebelumnya);

4) Presenting the stimulus (memberi stimulus);

5) Providing learning guidance (memberi petunjuk belajar);

6) Eliciting performance (memfasilitasi berkembangnya kinerja);

7) Providing feedback (memberi umpan balik);

8) Assessing performance (menilai kemampuan atau kinerja);

9) Enhancing retention and transfer (meningkatkan pemahaman dan transfer pengetahuan peserta didik).

Masing-masing dari sembilan peristiwa belajar tersebut dapat disertai dengan satu atau lebih aktivitas pembelajaran (instructional activity) yang dibedakan dengan istilah aktivitas belajar (learning activity). Namun tampaknya kesembilan peristiwa belajar di atas tidak seluruhnya dapat terintegrasi dalam proses pembelajaran. Oleh karena itu, peristiwa pembelajaran tersebut kemudian disederhanakan ke dalam lima komponen yang merupakan bagian dari strategi pembelajaran. Kelima komponen tersebut terdiri atas: (1) aktivitas sebelum pembelajaran, (2) penyajian isi pembelajaran, (3) partisipasi peserta didik, (4) penilaian, (5) aktivitas atau kegiatan tindak lanjut (Dick and Carey, 2009).

1. Mengembangkan aktivitas pembelajaran 
Secara sederhana aktivitas merupakan tugas dalam pembelajaran yang melibatkan pengalaman dan partisipasi langsung peserta didik. Aktivitas pembelajaran sering disebut dengan kegiatan belajar mengajar (KBM), yang merujuk pada berbagai aktivitas mulai dari aktivitas pendahuluan, inti, dan penutup. Istilah yang sering digunakan juga adalah proses belajar mengajar teaching learning process. (Banks, 2012: 1) memberi definisi tentang teaching learning process is a planned interaction that promotes behavioral change that is not a result of maturation or concidence (proses belajar mengajar adalah interaksi terencana yang mendorong perubahan perilaku yang bukan hasil dari kematangan atau kejadian yang kebetulan).

\section{$>\quad$ Aktivitas pendahuluan}

Aktivitas pendahuluan adalah suatu bentuk aktivitas awal untuk memberikan motivasi, menginformasikan pengetahuan dan keterampilan prasyarat yang harus dikuasai, dan tujuan atau standar kompetensi yang akan diperoleh dalam pembelajaran. John Keller (2010) memperkenalkan pendekatan model ARCS untuk menjadi dasar dalam membangun motivasi peserta didik dalam pelaksanaan pembelajaran, yang disimpulkan sebagai berikut:

$$
\begin{array}{ll}
\mathrm{A} & =\text { Attention (perhatian); } \\
\mathrm{R} & =\text { relevance (hubungan); } \\
\mathrm{C} & \text { = confidence (keyakinan); dan } \\
\mathrm{S} & \text { = satisfaction (kepuasan). }
\end{array}
$$

Tabel 1.

\begin{tabular}{|l|l|}
\hline \multicolumn{2}{|c|}{ Perhatian } \\
\hline Minat Persepsi & $\begin{array}{l}\text { Apa yang dapat saya lakukan untuk menarik minat } \\
\text { peserta didik? }\end{array}$ \\
\hline $\begin{array}{l}\text { Minat } \\
\text { penyelidikan }\end{array}$ & $\begin{array}{l}\text { Bagaimana saya dapat mendorong sikap } \\
\text { penyelidikan peserta didik? }\end{array}$ \\
\hline Beragam taktik & $\begin{array}{l}\text { Bagaimana saya dapat menggunakan berbagai taktik } \\
\text { untuk memelihara perhatian peserta didik? }\end{array}$ \\
\hline \multicolumn{2}{|c|}{ Hubungan } \\
\hline Orientasi tujuan & $\begin{array}{l}\text { Bagaimana saya dapat memenuhi kebutuhan } \\
\text { peserta didik? }\end{array}$ \\
\hline Kecocokan tujuan & $\begin{array}{l}\text { Kapan dan bagaimana saya dapat mempersiapkan } \\
\text { peserta didik dengan pilihan, tanggung jawab, dan } \\
\text { pengaruh yang tepat? }\end{array}$ \\
\hline Kebiasaan & $\begin{array}{l}\text { Bagaimana saya dapat membantu menghubungkan } \\
\text { pembelajaran dengan pengalaman peserta didik? }\end{array}$ \\
\hline \multicolumn{2}{|c|}{ Keyakinan } \\
\hline
\end{tabular}




\begin{tabular}{|l|l|}
\hline $\begin{array}{l}\text { Persyaratan } \\
\text { belajar }\end{array}$ & $\begin{array}{l}\text { Bagaimana saya dapat membantu mengembangkan } \\
\text { harapan positif menuju kesuksesan? }\end{array}$ \\
\hline $\begin{array}{l}\text { Kesempatan } \\
\text { keberhasilan }\end{array}$ & $\begin{array}{l}\text { Bagaimana pengalaman belajar dapat menunjang } \\
\text { keyakinan peserta didik terhadap kompetensi } \\
\text { mereka? }\end{array}$ \\
\hline $\begin{array}{l}\text { Pengawasan } \\
\text { personal }\end{array}$ & $\begin{array}{l}\text { Bagaimana peserta didik mengetahui bahwa } \\
\text { keberhasilan mereka betul-betul hasil dari kerja } \\
\text { keras dan kemampuan mereka? }\end{array}$ \\
\hline \multicolumn{1}{|c|}{ Kepuasan } \\
intrinsik & $\begin{array}{l}\text { Bagaimana saya dapat mempersiapkan kesempatan } \\
\text { yang berharga bagi peserta didik untuk } \\
\text { menggunakan pengetahuan dan keterampilan yang } \\
\text { baru diperoleh? }\end{array}$ \\
\hline Hadiah ekstrinsik & $\begin{array}{l}\text { Apa yang dapat dipersiapkan untuk memberikan } \\
\text { penguatan terhadap keberhasilan peserta didik? }\end{array}$ \\
\hline Persamaan & $\begin{array}{l}\text { Bagaimana saya dapat membantu peserta didik } \\
\text { dalam mempertahankan perasaan positif tentang } \\
\text { prestasi mereka? }\end{array}$ \\
\hline
\end{tabular}

Berdasarkan aktivitas pendahuluan terdiri atas dua bagian, yaitu aktivitas utama dan aktivitas pendukung. Aktivitas utama maksudnya adalah sesuatu yang harus ada. Adapun aktivitas pendukung boleh tidak ditulis dalam aktivitas pendahuluan, tetapi sering dilakukan pada saat pelaksanaan pembelajaran.

Tabel 2.

\begin{tabular}{|c|l|}
\hline Aktivitas & \multicolumn{1}{|c|}{ Jenis aktivitas } \\
\hline \multirow{4}{*}{ Pendahuluan } & $\begin{array}{l}\text { Aktivitas utama: } \\
\text { 1. Memberikan motivasi kepada peserta didik } \\
\text { (mencakup perhatian, relevansi, keyakinan diri, } \\
\text { dan kepuasan) } \\
\text { 2. Menginformasikan pengetahuan prasyarat } \\
\text { dan/atau apersepsi } \\
\text { 3. Menyampaikan tujuan atau standar kompetensi }\end{array}$ \\
\cline { 2 - 3 } & $\begin{array}{l}\text { Aktivitas pendukung: } \\
\text { a. Menyiapkan peserta didik secara psikis dan fisik } \\
\text { untuk mengikuti proses pembelajaran }\end{array}$ \\
& $\begin{array}{l}\text { b. Menyampaikan cakupan materi dan penjelasan } \\
\text { uraian kegiatan sesuai silabus. }\end{array}$ \\
\hline
\end{tabular}

\section{$>$ Aktivitas inti}

Pelaksanaan kegiatan inti merupakan proses pembelajaran untuk mencapai kompetensi dasar yang dilakukan secara interaktif, inspiratif, menyenangkan, menantang, memotivasi peserta didik untuk berpartisipasi aktif, serta memberikan ruang yang cukup bagi prakarsa, 
kreativitas, dan kemandirian sesuai dengan bakat, minat, dan perkembangan fisik serta psikologis peserta didik. Kegiatan inti menggunakan metode yang disesuaikan dengan karakteristik peserta didik dan mata pelajaran, yang dapat meliputi proses eksplorasi, elaborasi, dan konfirmasi (BSNP, 2007).

Tabel 3.

\begin{tabular}{|l|l|}
\hline Aktivitas & \multicolumn{1}{|c|}{ Jenis aktivitas } \\
\hline & $\begin{array}{l}\text { Aktivitas eksplorasi: } \\
\text { 1. Melibatkan peserta didik mencari informasi yang } \\
\text { luas dan dalam tentang topik/tema materi. } \\
\text { 2. Menggunakan beragam pendekatan pembelajaran, } \\
\text { media pembelajaran, dan sumber belajar. } \\
\text { 3. Memfasilitasi terjadinya interaksi multi-arah. } \\
\text { 4. Melibatkan peserta didik secara aktif dalam setiap } \\
\text { kegiatan pembelajaran. } \\
\text { 5. Memfasilitasi peserta didik melakukan percobaan di } \\
\text { laboratorium, studio, atau lapangan. }\end{array}$ \\
\cline { 2 - 3 } & $\begin{array}{l}\text { Aktivitas elaborasi: } \\
\text { Memfasilitasi peserta didik untuk membaca, menulis, } \\
\text { mengkaji, atau pemberian tugas, diskusi, dan lain-lain } \\
\text { agar memunculkan gagasan baru. } \\
\text { Memberi kesempatan untuk berpikir, menganalisa, } \\
\text { menyelesaikan masalah, dan bertindak tanpa ada rasa } \\
\text { takut. } \\
\text { Memfasilitasi peserta didik untuk kooperatif, kolaboratif, } \\
\text { atau berkompetisi secara sehat. } \\
\text { Memfasilitasi peserta didik membuat laporan } \\
\text { eksplorasi, menyajikan hasil kerja, dan/atau pameran, } \\
\text { turnamen, festival, serta produk yang dihasilkan. } \\
\text { Memfasilitasi peserta didik melakukan kegiatan yang } \\
\text { menunbuhkan kebanggaan dan rasa percaya diri } \\
\text { peserta didik. }\end{array}$ \\
\hline $\begin{array}{l}\text { Aktivitas konfirmasi: } \\
\text { Memberikan umpan balik positif dan penguatan dalam } \\
\text { bentuk lisan, tulisan, isyarat, maupun hadiah terhadap } \\
\text { keberhasilan peserta didik. } \\
\text { Memberikan konfirmasi terhadap hasil eksplorasi dan } \\
\text { elaborasi peserta didik melalui berbagai sumber. } \\
\text { Memfasilitasi peserta melakukan refleksi untuk } \\
\text { mendapat pengalaman belajar yang bermakna dalam } \\
\text { mencapai komptensi dasar. }\end{array}$ \\
\hline
\end{tabular}

Aktivitas penutup

Aktivitas penutup merupakan kegiatan yang dilakukan untuk mengakhiri aktivitas pembelajaran yang dapat dilakukan dalam bentuk rangkuman atau kesimpulan, 
penilaian dan refleksi, umpan balik, dan tindak lanjut. adapun bentuk kegiatan penutup dapat digambarkan pada tabel berikut:

Tabel 4

\begin{tabular}{|c|c|}
\hline Aktivitas & \multicolumn{1}{|c|}{ Jenis aktivitas } \\
\hline \multirow{5}{*}{ Penutup } & $\begin{array}{l}\text { Aktivitas penilaian: } \\
\text { 1. Bersama-sama dengan peserta didik atau sendiri } \\
\text { membuat rangkuman dan refleksi kegiatan yang } \\
\text { sudah dilakukan }\end{array}$ \\
& $\begin{array}{l}\text { 2. Melakukan penilaian terhadap kegiatan yang sudah } \\
\text { dilaksanakan secara konsisten dan terprogram }\end{array}$ \\
& $\begin{array}{l}\text { 3. Memberikan una pembelajaran pada pertemuan } \\
\text { berikutnya.mpan balik terhadap proses dan hasil } \\
\text { pembelajaran. }\end{array}$ \\
\cline { 2 - 3 } & $\begin{array}{l}\text { Aktivitas tindak lanjut: } \\
\text { 1. Merencanakan aktivitas tindak lanjut dalam bentuk } \\
\text { pembelajaran remedi, program pengayaan, layanan } \\
\text { konseling dan/atau memberikan tugas baik tugas } \\
\text { individual maupun kelompok sesuai dengan hasil } \\
\text { belajar peserta didik }\end{array}$ \\
2. Menyampaikan renc
\end{tabular}

\section{Mengembangkan metode pembelajaran}

Banyak sekali metode yang dapat digunakan dalam prses pembelajaran. Suparman (2012: 261-262) membagi metode pembelajaran ke dalam 20 macam yang dihubungkannya kompetensi dalam tujuan instruksional (pembelajaran) khusus. Hal ini dilakukan untuk memudahkan guru, dosen, instruktur dalam memilih metode yang sesuai dengan karakteristik peserta didik.

Tabel 5 .

\begin{tabular}{|c|c|}
\hline $\begin{array}{c}\text { Kecerdasan } \\
\text { jamak }\end{array}$ & \multicolumn{1}{c|}{ Metode \& gambaran umum } \\
\hline & $\begin{array}{c}\text { 1. Ceramah (lecture); penjelasan tentang materi } \\
\text { pembelajaran yang diberikan kepada peserta didik. } \\
\text { 2. Curah pendapat (brainstorming); pemaparan } \\
\text { tentang garis-garis besar ide yang melibatkan } \\
\text { sebagian atau seluruh peserta didik yang dipandu } \\
\text { oleh guru, dosen, atau instruktur dalam proses } \\
\text { pembelajaran; }\end{array}$ \\
& $\begin{array}{l}\text { 3endorong atau bercerita (storytelling); } \\
\text { penyampaian peristiwa melalui kata-kata, gambar, } \\
\text { atau suara yang dilakukan dengan improvisasi } \\
\text { untuk memperindah jalannya cerita. } \\
\text { Diskusi (discussion); tukar-menukar gagasan, } \\
\text { pemikiran, informasi, atau pengalaman diantara }\end{array}$ \\
\hline
\end{tabular}




\begin{tabular}{|c|c|}
\hline & $\begin{array}{l}\text { peserta didik, sehingga dicapai kesepakatan } \\
\text { pokok-pokok pikiran yang dipandu oleh moderator. }\end{array}$ \\
\hline Logis matematis & $\begin{array}{l}\text { 1. Penyelesaian masalah (problem solving); metode } \\
\text { yang melibatkan cara berpikir tingkat tinggi untuk } \\
\text { menemukan, mengubah, menyelesaikan berbagai } \\
\text { persoalan yang dihadapi } \\
\text { 2. Uji coba (experiment); pengujian pendapat, } \\
\text { pandangan, konsep atau teori yang dilakuka, baik } \\
\text { melalui laboratorium maupun melalui pengujian } \\
\text { fakta-fakta di lapangan } \\
\text { 3. Tanya jawab (socrates'questions); pengajuan } \\
\text { pertanyaan kritis kepada peserta didik yang } \\
\text { diangkat dari jawaban yang diberikan } \\
\text { 4. Berpikir kritis (critical thinking); suatu metode yang } \\
\text { melibatkan proses berpikir aktif, rasional, dan } \\
\text { reflektif untuk membuat keputusan berdasarkan } \\
\text { kajian mendalam dari bukti-bukti empiris. }\end{array}$ \\
\hline Visual spasial & $\begin{array}{l}\text { 1. Kiasan gambar (picture metaphors); perbandingan } \\
\text { satu ide dengan ide lainnya yang kelihatannya } \\
\text { tidak berhubungan yang bertujuan untuk } \\
\text { mengekspresikan konsep melalui gambar-gambar } \\
\text { visual. } \\
\text { 2. Pemetaan ide (ideas mapping); pengorganisasian } \\
\text { dan klarifikasi pikiran dengan cara visual melalui } \\
\text { penggunaan kata-kata kunci dan gambar } \\
\text { 3. Sketsa ide (idea sketching); pemberian materi } \\
\text { pembelajaran dengan melukis atau menggambar } \\
\text { sketsa dari suatu benda, orang, aaatau tempat } \\
\text { tanpa menguraikan dengan kata secara perinci } \\
\text { 4. Visualisasi (visualization); penggambaran ide-ide, } \\
\text { konsep, dan teori dalam bentuk papan ide, film, } \\
\text { atau screen video dalam pikiran tentang bahan } \\
\text { yang perlu dikuasai kemudian disimpan dalam } \\
\text { papan mental, seperti ejaan kata, rumus-rumus, } \\
\text { dan fakta-fakta sejarah. }\end{array}$ \\
\hline $\begin{array}{l}\text { Jasmaniah } \\
\text { kinestetik }\end{array}$ & $\begin{array}{l}\text { 1. Demonstrasi (demonstration); peragaan dan } \\
\text { pelaksanaan suatu konsep atau teori dengan } \\
\text { menggunakan anggota badan secara langsung } \\
\text { 2. Bermain peran (role play); metode pembelajaran } \\
\text { yang diarahkan untuk mengkreasi peristiwa } \\
\text { sejarah, mengkreasi peristiwa-peristiwa aktual, } \\
\text { atau kejadian-kejadian yang mungkin muncul pada } \\
\text { masa mendatang. } \\
\text { 3. Studi lapangan/karyawisata (field trip); kunjungan } \\
\text { lapangan yang dilakukan bersama dengan peserta } \\
\text { didik untuk melihat secara langsung kesesuaian } \\
\text { antara teori dan konsep dengan fakta di lapangan } \\
\text { 4. Berpantomim (pantomym); peragaan atau } \\
\text { perbuatan tanpa kata sebagai bentuk ekspresi } \\
\text { pendapat, pandangan, atau kritik. }\end{array}$ \\
\hline Musikal beriram & 1. Diskografi (discography); pengintegrasian lagu- \\
\hline
\end{tabular}




\begin{tabular}{|c|c|}
\hline & $\begin{array}{l}\text { lagu sebagai hasil karya seni dengan topik-topik } \\
\text { pembahasan dalam pembelajaran. Setiap kali } \\
\text { pembahasan tentang suatu tema atau topik } \\
\text { tertentu dikaitkan dengan lagu-lagu yang biasa } \\
\text { diciptakan untuk kebutuhan pembelajaran } \\
\text { 2. Sugestopedia (suggestopedia); pemanfaatan } \\
\text { lingkungan belajar yang nyaman disertai dengan } \\
\text { musik, gambar, dan pewarnaan dengan } \\
\text { keterlibatan peserta didik secara aktif } \\
\text { 3. Musik instrumen (instrumental music); penyajian } \\
\text { pembelajaran yang dibarengi dengan alunan musik } \\
\text { yang diatur jenis musik, volume, dan kondisi } \\
\text { ruangannya. } \\
\text { 4. Pengkondisian suasana musik (musical } \\
\text { conditioning); penyajian materi yang melibatkan } \\
\text { penciptaan suasana musik ketika menyajikan, } \\
\text { berdiskusi, berjalan di dalam kelas dengan } \\
\text { mengatur suara, panjang pendek ucapan, dan } \\
\text { intonasi serta gelombang suara. }\end{array}$ \\
\hline Interpersonal & $\begin{array}{l}\text { 1. Jigsaw; tipe belajar kooperatif yang menekankan } \\
\text { kerja sama, memberi tanggung jawab, dan empati } \\
\text { dengan pemberian tugas untuk dilakukan oleh } \\
\text { semua anggota dalam kelompok } \\
\text { 2. Mengajar teman sebaya (peer tutoring); pemberian } \\
\text { tugas pembelajaran yang dilakukan dengan } \\
\text { bantuan teman sebaya } \\
\text { 3. Belajar beregu (teamwork); belajar bersama yang } \\
\text { dilakukan oleh sekelompok peserta didik dimana } \\
\text { minat dan pendapat dari setiap anggota dapat } \\
\text { menjadi subordinat dari penyatuan kelompok. } \\
\text { 4. Permainan (games); suatu bentuk permainan } \\
\text { dalam pembelajaran yang melibatkan proses } \\
\text { pemanasan (ice-breaker) atau penyegaran } \\
\text { (energizer) untuk pemecah situasi } \\
\text { 5. Kebekuan pikiran atau fisik peserta didik }\end{array}$ \\
\hline Intrapersonal & $\begin{array}{l}\text { 1. Studi mandiri (independent study); pemberian } \\
\text { tugas yang dilakukan secara mandiri oleh peserta } \\
\text { didik dalam jangka waktu tertentu tanpa bantuan } \\
\text { dari peserta didik yang lain, tetapi dapat } \\
\text { berkonsultasi dengan guru, dosen, atau instruktur } \\
\text { jika mendapat kesulitan } \\
\text { 2. Belajar dengan alat bantu komputer (computer } \\
\text { assisted learning); seperangkat aktivitas } \\
\text { pembelajaran terprogram yang menggunakan } \\
\text { basis komputer sebagai alat bantu } \\
\text { 3. Refleksi (reflective learning); pembelajaran yang } \\
\text { menekankan pada ketersambungan atau } \\
\text { keterhubungan proses assimilasi, akomodasi, dan } \\
\text { ekuilibrasi dalam mengkonstruksi pengetahuan } \\
\text { baru } \\
\text { 4. Belajar dengan pengaturan sendiri (self goal }\end{array}$ \\
\hline
\end{tabular}




\begin{tabular}{|c|c|}
\hline & $\begin{array}{l}\text { setting); pembelajaran yang menekankan pada } \\
\text { keterampilan mengorganissi tujuan dan aktivitas } \\
\text { pembelajaran yang dilakukan sendiri oleh peserta } \\
\text { didik }\end{array}$ \\
\hline Naturalistik & $\begin{array}{l}\text { 1. Belajar melalui alam (learning through nature); } \\
\text { pemanfaatan alam sebagai sumber, media, bahan, } \\
\text { dan objek kajian dengan melibatkan partisipasi } \\
\text { aktif dari peserta didik }\end{array}$ \\
$\begin{array}{c}\text { 2. Jendela belajar (windows of learning); } \\
\text { pemanfaatan pintu atau jendela sebagai ruang } \\
\text { untuk melihat keluar tentang keadaan alam seperti } \\
\text { tumbuh-tumbuhan, binatang, matahari, hujan, dan } \\
\text { pelangi. }\end{array}$ \\
\hline 1. Respons peristiwa: pemberian respons pada suatu \\
peristiwa atau kejadian penting dalam kehidupan \\
masyarakat dan mengaitkan dengan berbagai \\
materi yang dipelajari. Jika perlu peristiwa atau \\
kejadian diangkat sebagai suatu materi \\
pembelajaran
\end{tabular}

3. Mengembangkan media pembelajaran

Pengembangan media pembelajaran mengarah pada pemilihan media yang digunakan dalam pembelajaran.scanland (2012) memberikan definisi tentang media sebagai berikut:

"instructional media encompasses all the materials and physical means an instructor might use to implement instruction and facilitate student's achievement of instructional objectives. This may include traditional materials such as chalkboards, handouts, charts, slides, overheads, real objects, and videotape or film, as well newer materials and methods such as computers, DVDs, CDRoms, the internet, and interactive video conferencing."

Definisi di atas menggambarkan bahwa media pembelajaran meliputi semua bahan dan peralatan fisik yang digunakan instruktur untuk melaksanakan pembelajaran dan memfasilitasi prestasi peserta didik. Media pembelajaran termasuk bahan-bahan tradisional seperti papan tulis, handout, grafik, slide, overhead,benda nyata, dan rekaman video atau film, serta bahan-bahan baru dan metode seperti komputer, DVD, CD-ROM, internet, dan konferensi video interaktif. 


\section{$>$ Pemilihan media pembelajaran}

Menurut Tiare dalam Smaldino, Lowther, dan Russell (2008: 101) ada beberapa petunjuk teknis dalam memilih media pembelajaran yang sesuai, diantaranya:

1) Searah dengan standar, tujuan pembelajaran (umum dan khusus)

2) Kesesuaian umur dan kemampuan bahasa

3) Tingkat kemenarikan dan keterlibatan jika media itu digunakan

4) Kualitas teknis yang merujuk pada keterjangkauan media yang dipilih

5) Kemudahan penggunaan dan pengoperasiannya

6) Bebas bias

7) Dilengkapi dengan petunjuk penggunaannya

$>$ Jenis media pembelajaran

Heinich, Molenda, Russell, dan Smaldino (2002) mengelompokkan media pembelajaran ke dalam beberapa jenis, yaitu:

1) Media cetak

2) Media pameran (display)

3) Media audio

4) Media visual

5) Media video

6) Multimedia

7) Media komputer

8) Komputer dan jaringan.

\section{Kesimpulan}

Pendekatan merupakan sudut pandang bagi guru, dosen, atau instruktur atau pengembang terhadap proses pembelajaran, seperti pendekatan yang berpusat pada guru, dosen, atau instruktur dan pendekatan yang berpusat pada peserta didik. Metode merupakan upaya untuk mengimplementasikan rencana yang sudah disusun dalam kegiatan nyata agar tujuan yang telah disusun tercapai secara optimal. Teknik adalah cara yang dilakukan seseorang dalam rangka mengimplementasikan suatu metode. Taktik dalam pembelajaran merupakan gaya yang diperankan oleh pendidik secara individu dalam mengimplementasikan teknik atau metode tertentu.

Komponen umum startegi pembelajaran mencakup menarik perhatian, menjelaskan tujuan pembelajaran, 
mengingatkan pengetahuan sebelumnya, memberi stimulus, memberi petunjuk belajar, memfasilitasi berkembangnya kinerja, memberi umpan balik, menilai kemampuan atau kinerja, dan meningkatkan pemahaman dan transfer pengetahuan peserta didik. Aktivitas pembelajaran mencakup aktivitas pendahuluan, inti, dan penutup. terdapat banyak sekali metode yang dapat digunakan dalam pembelajaran. Guru, dosen atau instruktur diharapkan mampu memilih metode yang sesuai dengan tujuan, materi, dan media pembelajaran. Media pembelajaran mencakup media cetak, pameran visual, audio, video, komputer, multimedia, komputer dan jaringan.

\section{Daftar Pustaka}

Banks, Teressa. Teaching-learning Process. Online: http://www.ncdhh.gov/dhsr/hcpr/pdf/PrinciplesofAdultLea rning2007.pdf2014

Direktorat Tenaga Kependidikan. Strategi Pembelajaran dan Pemilihannya. Jakarta: Direktorat Jenderal Peningkatan Mutu Pendidikan dan Tenaga Kependidikan Departemen Pendidikan Nasional. 2008

Dieudonne' Leclercg dan Marianne Poumay. The 8 Learning Events Model and its Principles. 2011

Reigeluth, Charles $M$ dan Carr-Chellman, Alison $\mathrm{A}$. Instructional-Design Theories and Models Volume III: Building a Common Knowledge Base. New York: Routledge. 2009

Richards, Jack $\mathrm{C}$ dan Rodgers, Theodore S. Approaches and Methods in Language Teaching: $A$ description and analysis. Cambridge: Cambridge University Press. 1986

Scanlan, Craig L. Instructional Media: Selection and Use. Online:

http://www.umdni.edu/idsweb/idst5330/instructionalmedia.htm. 2012

Smaldino, Sharon E., Lowther, Deborah L., dan Russell, James D. Instructional Technology and Media for Learning. Upper Saddle River, New Jersey: Pearson. 2008

Suparman, M. Atwi. Desain Instructional. Jakarta: Universitas Terbuka. 2010 